\title{
Openness and Diversity in Journal
}

\section{Editorial Boards: Patterns of Gender}

and International Diversity in Open

\section{Science Publications and Open Access}

\section{Journals}

[Draft 3/29/2022]

\author{
Micah Altman* \\ Massachusetts Institute of Technology \\ escience@mit.edu \\ (585) 466-4224 \\ Office of the Director \\ MIT Libraries, Building NE36-6101 \\ 77 Massachusetts Avenue
}

Cambridge, MA 02139-4307

\footnotetext{
${ }^{*}$ Corresponding author.
}

Philip N. Cohen

University of Maryland

pnc@umd.edu

(301) 405-6414
Department of Sociology, 2112 Parren Mitchell Art-Sociology Building (Bldg 146), 3834 Campus Drive

College Park, MD 20742 


\section{ABSTRACT}

This study aims to measure diversity in scholarly journals' editorial board structure and characterize patterns of editorial diversity across types of journals. To accomplish these aims, we integrate multiple sources of data at the journal and editor level to assemble a novel database describing the composition of editors and editorial boards for more than six thousand journals internationally, characterized by discipline, commercial publishing model, and research transparency. We then apply name-based gender imputation, geo-entity extraction analysis, and standardized dispersion measures to evaluate each group's diversity. This analysis reveals that editorial leadership is more homogenous than editorial boards, and that diversity across both boards and leadership varies substantially (and robustly) across disciplines. Open-access journals' boards exhibit less gender diversity and more international diversity than their closed-access counterparts. These results also suggest that open access, open science, and diversity, and equity, and inclusion are not strongly correlated and thus require separate measurements.

\section{INTRODUCTION}

The identity of officeholders is related to inequalities within organizations and the outcomes of their work. In academic institutions, research journals present opportunities to develop academic careers through editorships and editorial board positions, and other influential positions that shape academics' careers in all fields. Thus, the study of editorships and editorial boards is essential for understanding equity, diversity, and inclusion within academic settings. Academic journals remain at the core of institutional hierarchies, providing opportunities for leadership and career advancement -- as well as venues for developing and showcasing 
research from diverse positions and perspectives. As with other industries [1], the demographic composition of leadership positions at academic journals represents both a critical outcome and a potential driver of equity in the research industry more generally. In addition to editor positions, service on editorial boards matters as well. "A chain runs from editorial board decisions, to papers published by academics, to ratings assigned to organizations employing such academics, to finances channeled to organizations in some proportion to rankings" [2]. At the same time that publishers and journals have faced questions about the diversity of their leadership teams, they have also considered (and in many cases embraced) greater openness in their publishing models and their approach to research transparency. This study addresses the gender and national diversity of editors and editorial boards at more than six thousand journals and the association of that diversity with publishing models and research transparency across academic disciplines.

In addition, although the mechanisms for producing diversity in leadership at academic journals are beyond the scope of our analysis, the data allow us to consider the interconnection between journals, as represented by the individuals holding positions at multiple journals. Such linkages between journals, like those between other organizations' boards of directors, represent potential pathways for career advancement, which could hinder or promote diversity in leadership structures.

A robust literature connects the presence of women and members of minority groups in leadership positions with measures of inequality within organizations. For example, women in leadership positions may provide better mentoring for female subordinates, less cognitive bias or discrimination, and more support for equalizing policies and practices [3]. This connection has been found, for example, in Fortune 1000 companies with women executives, managers, and members of boards of directors [4]. Furthermore, in US federal government agencies, the representation of women in management has a beneficial effect on the subjective experiences 
of their female subordinates [5]. Further, companies that share directors with more gender-integrated boards have higher odds of having women on their own boards [6]. On the other hand, dense networks can represent more forceful gatekeeping in a profession. In the case of elite journals, for example, some disciplines (such as business) show significant overlapping editorial board memberships, which raises the specter of "academic patronage" [2].

The direct role of editors in promoting academic career advancement has been shown, for example, in the effects of male bias in invited commentaries for medical journals [7]. Research on the peer review process has found that all-male reviewer teams were more likely to favor submissions with male authors [8]. Given the evidence for same-gender preference in peer-reviewing, the underrepresentation of women in editorial positions poses a problem for gender equity in academic careers [9]. Unsurprisingly, these processes and disparities vary across academic disciplines, which show marked heterogeneity in gender disparities [10]. Studies in mathematics [11], management studies [2,12,13], biological sciences [14], neuroscience [21], and medical disciplines [15-17], among others, have found gender disparities in editorial leadership positions.

A parallel literature investigates the international diversity of editorial leadership positions and outcomes associated with international diversity. For example, among 165 journals published by Hindawi, $76 \%$ of editors were affiliated with institutions in Europe or North America [18]. Similarly, a study of 6916 people in editorial positions at 246 leading economics journals found that $46 \%$ were affiliated with US institutions, and $30 \%$ were affiliated with European institutions [19]. Similar dominance was found in environmental biology [20], and public health [22] journals. As with gender, a positive association has been found between homogeneity by country of origin and acceptance of peer-reviewed papers [8], and also that journals with more geographically diverse editorial boards publish more diverse research articles [23]. 
At least conceptually, the goals of increased equity and greater openness and transparency have been linked $[24,25]$. Thus, we also investigate whether editor and editorial board diversity varies across types of journals by their business model in addition to differences across disciplines. As academic disciplines and institutions have confronted the challenges of diversity, equity, and inclusion, some have also embraced the movement toward open access in publishing and research transparency. Indeed, one expressed motivation for open access and transparency is to reduce resource inequality and barriers to participation in research and learning. Furthermore, journals engaged in open access publishing and research transparency may have more gender and international diversity among their editors and editorial boards if they are motivated by egalitarian ends.

To analyze such questions, large studies of gender composition in academic publishing rely on automated analysis based on names [26], albeit with error, as we perform here (see below). And individuals may be associated with countries through their institutional affiliation, using data from journal websites. However, other potential identities of interest, such as race or ethnicity, are not readily discernible automatically at scale, which probably explains why research in this area concentrates on gender and regions of institutional affiliation.

Our results do not show a strong link within individual journals between open access and inclusion. We find a lower representation of women and less national diversity at the highest level of the editorial hierarchy (editors-in-chief) and distinct patterns of inclusion and diversity across disciplines. Across disciplines, some that display a greater representation of women are less inclusive of diverse national origins, and vice versa. Thus, one should not presume that multiple forms of diversity are connected; nor that diversity, open access, and transparency reinforce each other. 


\section{DATA}

This analysis integrates four separate independent sources of data which together characterize journal and editor characteristics. Our primary source of data on editors is the dataset of journal editorial board positions assembled by Pacher and colleagues [27] -- this is a Wikimedia-supported effort that extracted editor lists using web-mining methods on the catalogs of targeted journal publishers. This data, collected in February 2021, comprises 17 publishers, 6090 journals, and 478563 named editor roles. (Some individuals serve multiple roles within or across journals, so the number of individuals observed is smaller.)

We selected this data source because of its uniqueness, novelty, and large size. However, it is limited to a subset of publishers, and some large publishers (particularly Wiley and Taylor \& Francis) are excluded. Figure 1 shows the publishers and the number of journals included. Moreover, the dataset provides only minimal information: journal names and ISBNs; and the name, role, and affiliation of individuals associated with each journal. 


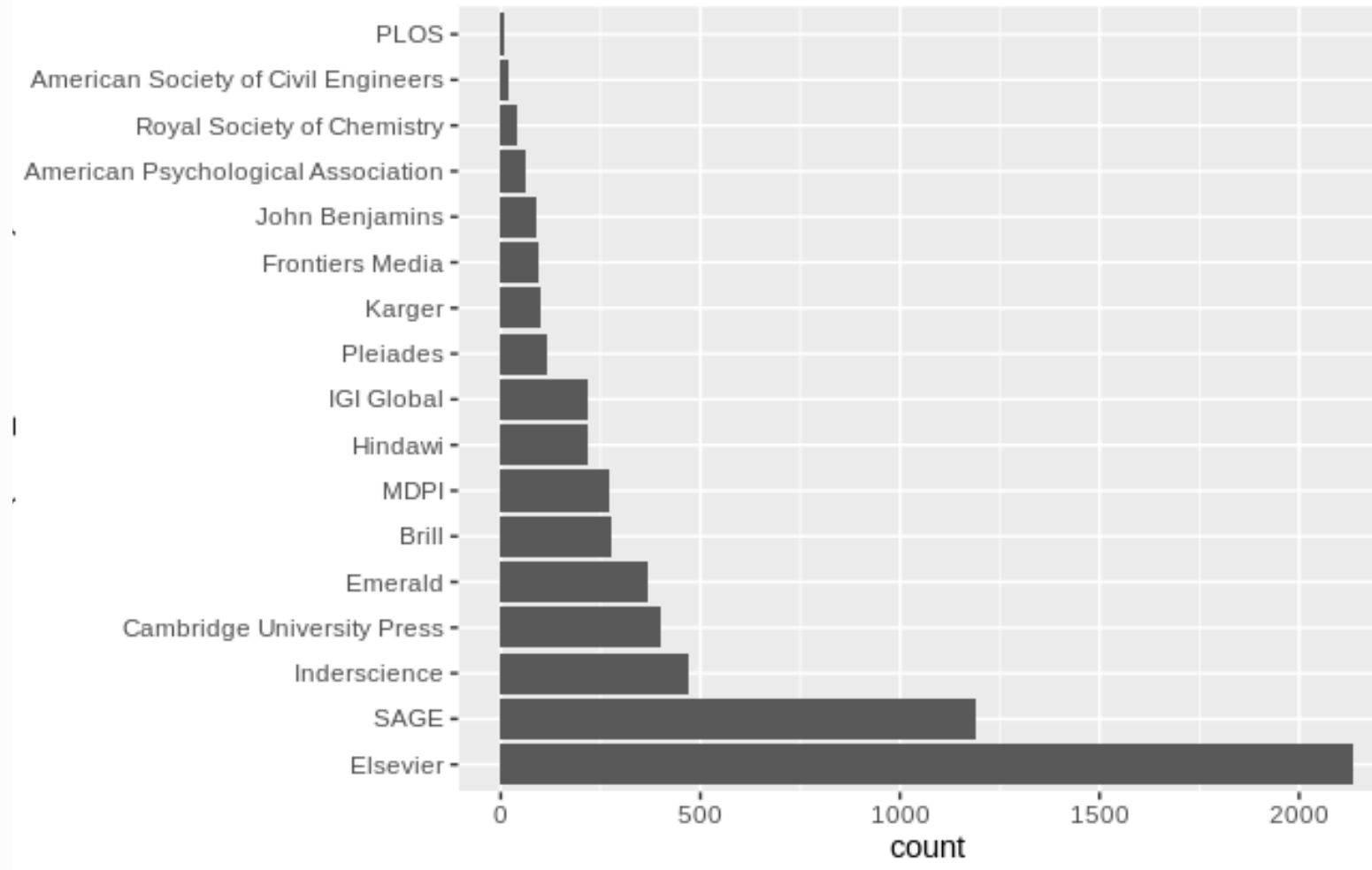

Figure 1 Distribution of Journals By Publisher

The dataset also has undocumented limitations related to data consistency and completeness: Many journals are missing ISSNs, author names are often abbreviated, editorial roles are unstandardized, and organizational fields are unstandardized. Further, many data problems are inherited from parsing problems in the web-mining approach, resulting in a substantial rate of missing or semantically incorrect information (e.g., addresses that are read as names). For example, although editorial roles generally fall into four main conceptual categories (chief, editor, board, publisher/other), the role variable takes on thousands of different values: Many of these are clearly data crawling errors, and almost all of the remaining errors stem from minor variations in terminology. 
Because of these limitations, we apply a set of data cleaning operations prior to geographic entity extraction and gender recognition. Replication materials for this paper are available from GitHub: https://github.com/MIT-Informatics/EditorAnalysis. The replication materials include copies of the processed and necessary code to retrieve the original data sources, clean and link them, compute all of the measures described below, and reproduce each figure and table.

We apply a dictionary of computer-assisted (manually designed, automatically applied) rules to check and clean the data before entity extraction. We use exact and fuzzy-string matching across the other data sources describing journals (described below) to fill in missing ISSN numbers for over 2500 journals. We then use ISSNs to perform linkage with other journal-level information sources to classify each journal by discipline, open-access policy, and open science policy:

1. We use codes assigned by the Australian national government as part of its national research assessment process to classify journals by discipline (see [28] for more details). The ERA classification of journals produced through this process assigns journals multiple standardized codes. ERA has been refined and regularly updated over a decade, most recently in 2018. It provides a comprehensive expert labeling of a large number of journals (more than 25,000). Journals are assigned up to three individual codes, or "multidisciplinary" if their audiences extends to more than three major disciplines. These codes are hierarchical -- grouping 179 fields into ten broad categories.

2. We use the Directory of Open Access Journals (DOAJ) [29] to identify whether a journal publishes all articles under an open access license. Established in 2003, the DOAJ is the most comprehensive catalog of open access journals, and registration of OA journals in it is considered best practice.

3. To identify research transparency practices, we use the Transparency and Openness Promotion Guidelines (TOP). The TOP methodology was proposed in 2015 [30] and has 
been adopted by approximately 5,000 journals. The Center for Open Science provides data on organizations that became TOP signatories through 2020. Further COS scores the transparency of journals on multiple dimensions -- however it has not yet produced scores for all signatories.

\section{METHODS}

Available data identifies editors only with a character string representing full name (including honorifics) and affiliation. We employ a multi-stage process to clean and process these strings to standardize them, match unique individuals across repeated entries, identify the institutional location, and impute gender.

(Currently, publishers provide editor information only in unstructured text form. Publisher adoption of ORCID identifiers would support unambiguous identification of individuals and their associated institutions. Regardless, no current researcher profile system provides information on gender and other diversity characteristics.)

For all character fields, we use the Tidyverse stringr [31] utilities to normalize character sets, remove special characters that do not appear in names (e.g., trademark symbols, emojis), and standardize whitespace across all character fields. For editor name fields, we conduct the following cleaning and imputation steps:

- Clean name strings using a set of automated (regular expression based) editing rules, adapted to this database, to separate honorifics from name components;

- Extract separate name components (surname, given name, middle name) using regular expressions with the humaniformat [32] tool;

- Statistically impute gender from given names, using the gender [33,34] tool. 
Because no systematic public data on self-reported author characteristics exists, however, research on participation in scholarly publications must use bibliometric methods to impute gender from author names. (See, for example, [35])

To impute editors' gender, we apply a commonly used method in scientometric analysis to impute gender based on author names. This method is intended for aggregate analysis and coarse (binary) classification and not for individual-level analysis -- e.g., assigning a pronoun to a specific author. We applied the genderize method [36], based on individual self-identification of gender on social media platforms. We use propensity-weights (proportions of the name-gender assignment in the observed population) to compute aggregate estimates -- this yields unbiased summary statistics. Although we do not report confidence intervals within these tables, these are relatively narrow because each subgroup contains thousands to hundreds of thousands of samples. As a sensitivity check for measurement error, we replicated our analyses using the IPUMS corpus of historical censuses [37] -- as it is the most extensive alternative corpus available. The substantive conclusions reported below are robust to the choice of gender extraction method.

For each editor, we identify the country of the institution with which they are affiliated. This identification process involves parsing the affiliation string to separate institutional name and location components, applying database-specific regular expressions to clean the location information, and applying a gazetteer to the location component to extract country.

Specifically, we use the open-source Geonames gazetteer, which uses a crowd-sourced database, and is one of the most well-used gazetteers in academic work. While this gazetteer has some gaps in coverage for geographic fields in less-populated areas of countries, it provides coverage of the populated regions (in which research institutions are typically located), making it appropriate for association at the country level [38]. 
We used a regular-expression-based approach to match the location portion of affiliation statements to gazetteer entries using the geotext library. This approach is generally comparable in recall performance to NLP methods, although it requires more data cleaning to eliminate false positives [39]. Fortunately, because the affiliation field information in the dataset is short and semi-structured, potential miscodings could be detected with additional regex-based cleaning rules.

We construct a measure of national diversity using an inverse Herfindahl-Hirschman index $[40,41]$, which ranges from 0 for boards where all members are from the same country to 1 for those with the maximum possible diversity.

\section{RESULTS}

\subsection{Ecosystem-level characteristics: editors, journals \& boards}

The editors' roles are dominated by people with institutional affiliations in the United States, representing $29 \%$ of editors with identifiable national locations. ( Approximately $96 \%$ of editorial positions could be matched to a country. ) Great Britain holds the next largest share, with $8 \%$ of the identifiable total, followed by Italy (7\%) and China (7\%). Figure 2 maps the distribution of editors worldwide.

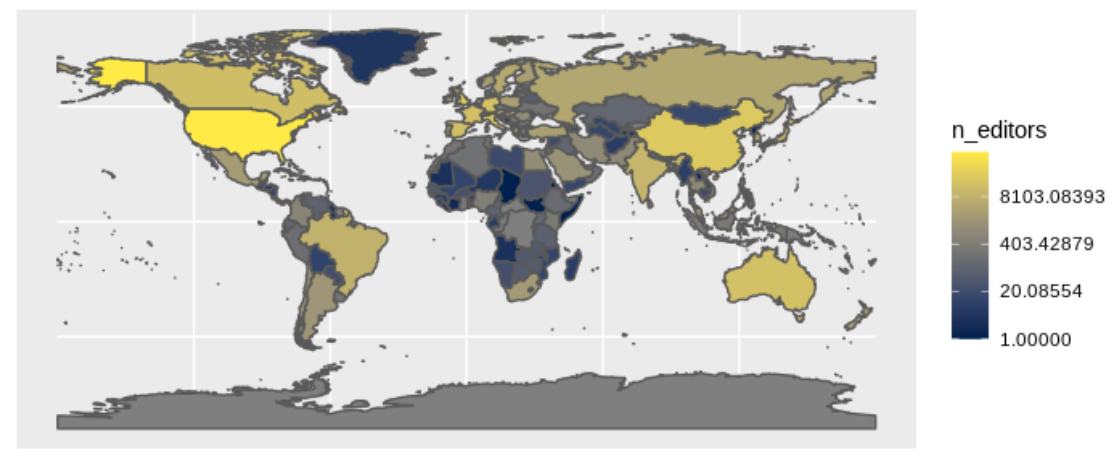

Fig 2. Distribution of journal editors by country. 
The twenty countries with the greatest share of editors, accounting for $85 \%$ of total editors, are displayed in Table 1. Besides the US, Great Britain, and European nations the only countries with more than $4 \%$ of editors are China (6\%) and Australia (4\%).

\begin{tabular}{|c|c|c|c|c|c|}
\hline \multicolumn{6}{|c|}{ Roles by Country } \\
\hline & & & & \multirow[t]{2}{*}{ Total } & \multirow[t]{2}{*}{$\%$} \\
\hline & editor & review & chief & & \\
\hline US & 41279 & 87976 & 1632 & 133836 & $28 \%$ \\
\hline GB & 12049 & 25911 & 769 & 39542 & $8 \%$ \\
\hline IT & 8664 & 22619 & 160 & 31818 & $7 \%$ \\
\hline $\mathrm{CN}$ & 8744 & 17810 & 406 & 27448 & $6 \%$ \\
\hline Unknown & 5441 & 11437 & 814 & 20778 & $4 \%$ \\
\hline $\mathrm{DE}$ & 6192 & 13340 & 191 & 19942 & $4 \%$ \\
\hline $\mathrm{AU}$ & 5551 & 11871 & 201 & 17845 & $4 \%$ \\
\hline FR & 4855 & 11025 & 247 & 16471 & $3 \%$ \\
\hline ES & 4724 & 11089 & 149 & 16160 & $3 \%$ \\
\hline $\mathrm{CA}$ & 4777 & 10594 & 193 & 15784 & $3 \%$ \\
\hline $\mathrm{JP}$ & 3230 & 8352 & 92 & 11792 & $2 \%$ \\
\hline IN & 3429 & 6273 & 76 & 9930 & $2 \%$ \\
\hline $\mathrm{NL}$ & 2704 & 5307 & 131 & 8235 & $2 \%$ \\
\hline $\mathrm{BR}$ & 2357 & 5190 & 36 & 7664 & $2 \%$ \\
\hline $\mathrm{CH}$ & 1977 & 4083 & 80 & 6246 & $1 \%$ \\
\hline $\mathrm{KR}$ & 1312 & 3915 & 43 & 5421 & $1 \%$ \\
\hline SE & 1467 & 3329 & 53 & 4924 & $1 \%$ \\
\hline$\overline{\mathrm{PT}}$ & 1533 & 3100 & 36 & 4696 & $1 \%$ \\
\hline GR & 1174 & 3042 & 40 & 4338 & $1 \%$ \\
\hline $\mathrm{RU}$ & 641 & 3282 & 300 & 4240 & $1 \%$ \\
\hline
\end{tabular}

Table 1. Editorial Roles by country.

(Higher percentage value are highlighted with shading. )

For those with an identified gender (approximately $71 \%$ of the total) a minority $(34 \%)$ are female. Among editors in chief, which make up approximately $1 \%$ of the data, $22 \%$ are categorized as female, while those identified as editors (36\% female) and reviewers (34\% female) have a somewhat greater representation of women (Fig 2). 


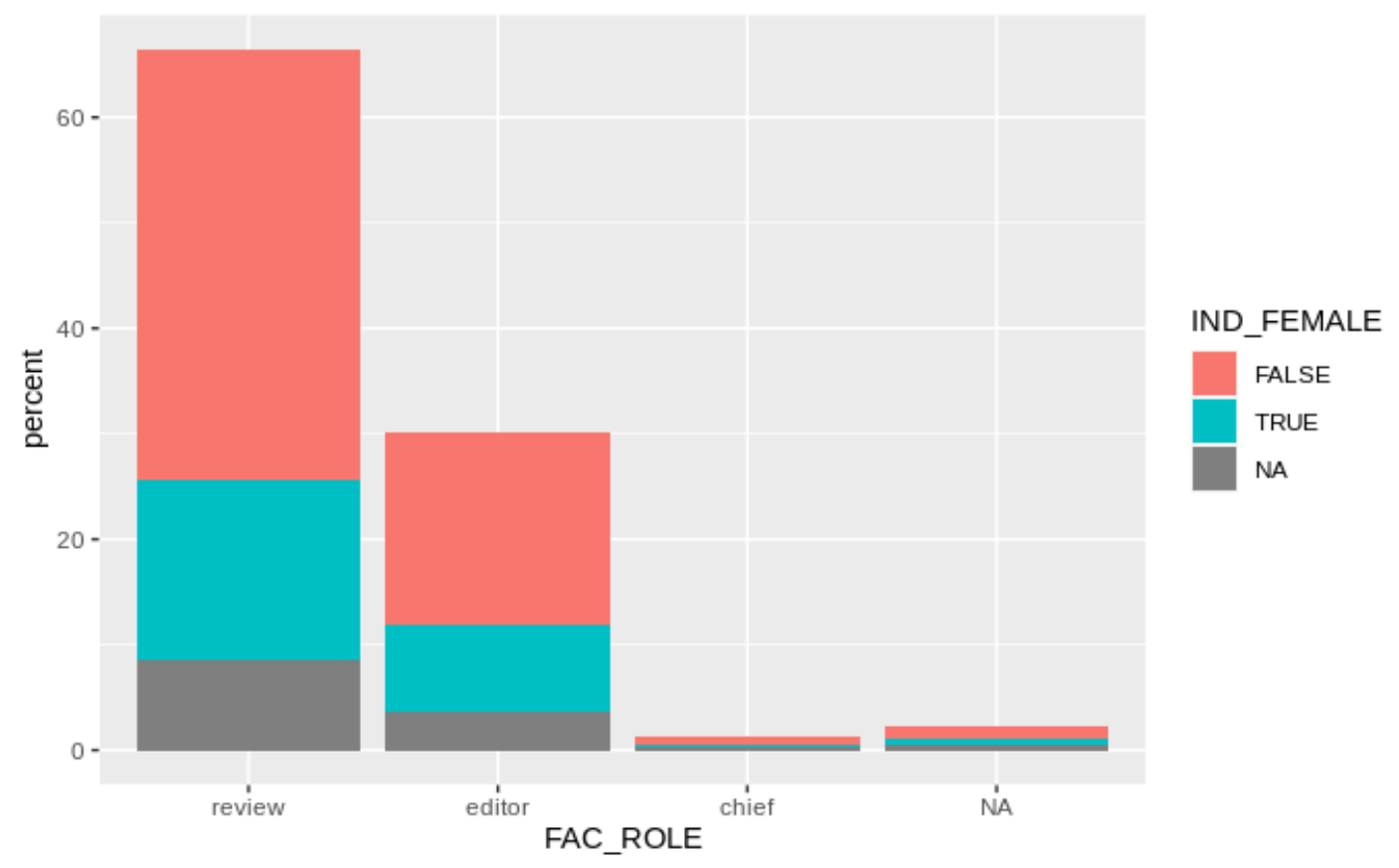

Fig 3. Distribution of journal editors by gender.

The data include 17 publishers (Table 2). The range in the number of journals per publisher (15 for PLOS to 3495 for Elsevier) reflects differences in both size and publishing model. Some individual journals have thousands of editors and editorial board members. For example, PLOS One and Frontiers in Psychology each have more than 9,000 individual members (editors and board members) in the dataset. The commercial models represented include all-OA publishers such as PLOS, majority-OA publishers such as MDPI, and those with few or no OA journals, including industry leaders such as Elsevier (12\% OA) and Sage (11\%). Open science practices, as reflected in TOP adoption, were observed for a high of $84 \%$ of Elsevier, Frontiers (64\%), PLOS (60\%), and Emerald (60\%), while some publishers have no TOP journals (IGI and Inderscience). 


\begin{tabular}{|c|c|c|c|c|c|}
\hline \multicolumn{6}{|c|}{ Journal Characteristics } \\
\hline & \# of journals & $\%$ open access & $\begin{array}{l}\% \text { open } \\
\text { science }\end{array}$ & $\begin{array}{c}\# \text { members } \\
\text { (mean) }\end{array}$ & [Range] \\
\hline \begin{tabular}{|l} 
American \\
Psychological \\
Association
\end{tabular} & 111 & $0 \%$ & $11 \%$ & 65.1 & $3-171$ \\
\hline \begin{tabular}{|l|} 
American \\
Society of Civil \\
Engineers
\end{tabular} & 39 & $0 \%$ & $8 \%$ & 44.8 & $10-106$ \\
\hline Brill & 327 & $2 \%$ & $57 \%$ & 21.1 & $1-85$ \\
\hline \begin{tabular}{|l|} 
Cambridge \\
University \\
Press \\
\end{tabular} & 548 & $5 \%$ & $27 \%$ & 32.5 & $1-331$ \\
\hline Elsevier & 3491 & $12 \%$ & $84 \%$ & 50.3 & $1-428$ \\
\hline Emerald & 583 & $6 \%$ & $60 \%$ & 48.6 & $1-245$ \\
\hline Frontiers Media & 135 & $81 \%$ & $64 \%$ & $2,359.0$ & $1-9961$ \\
\hline Hindawi & 314 & $98 \%$ & $1 \%$ & 72.4 & $6-1710$ \\
\hline IGI Global & 292 & $0 \%$ & $0 \%$ & 47.6 & $3-219$ \\
\hline Inderscience & 681 & $0 \%$ & $0 \%$ & 36.7 & $1-187$ \\
\hline $\begin{array}{l}\text { John } \\
\text { Benjamins }\end{array}$ & 128 & $0 \%$ & $15 \%$ & 28.8 & $6-62$ \\
\hline Karger & 123 & $19 \%$ & $5 \%$ & 36.2 & $1-94$ \\
\hline MDPI & 334 & $81 \%$ & $57 \%$ & 155.5 & $5-869$ \\
\hline Pleiades & 160 & $0 \%$ & $54 \%$ & 27.5 & $10-59$ \\
\hline PLOS & 15 & $100 \%$ & $60 \%$ & 828.5 & $6-9219$ \\
\hline $\begin{array}{l}\text { Royal Society } \\
\text { of Chemistry }\end{array}$ & 72 & $6 \%$ & $6 \%$ & 52.1 & $1-103$ \\
\hline SAGE & 1877 & $11 \%$ & $9 \%$ & 49.1 & $1-369$ \\
\hline
\end{tabular}

Table 2. Journal characteristics by publisher.

(Higher percentage value are highlighted with shading. )

\subsection{Correlates of diversity: discipline, publisher, openness, and transparency}

Figure 4 shows the distribution of gender representation and national diversity for journals by OA and TOP status. Representation of women is higher (in the editor and reviewer ranks) in closed journals, but international diversity is higher in open journals. Aggregating TOP journals within the open- and closed- categories reveals that TOP journals have more international 
diversity (conditional on open/closed status). Overall, however, these differences are relatively small.
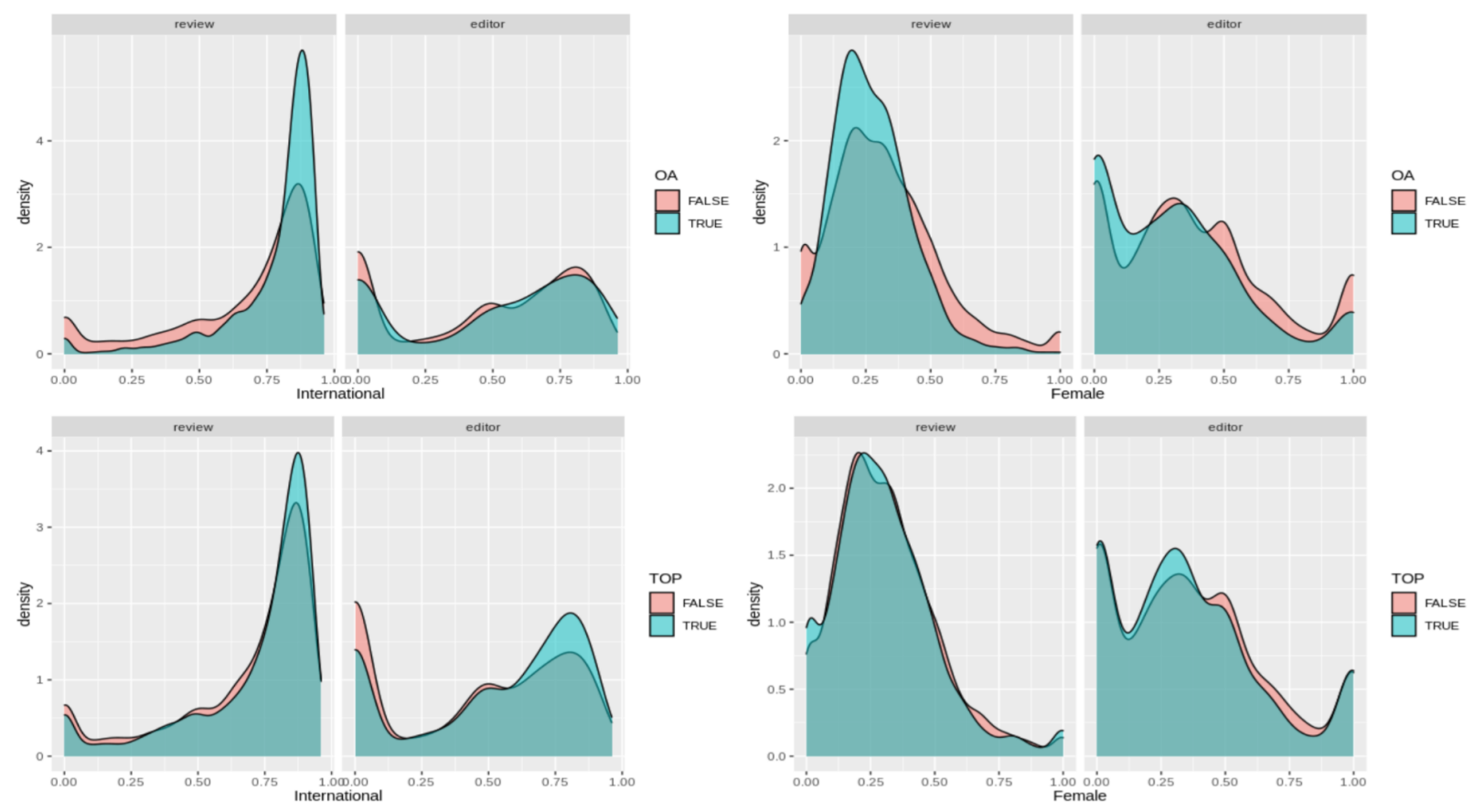

Fig 4. Board-wide diversity by editorial role, OA, and TOP status.

We compute diversity measures of diversity for editors and reviewers at the journal level. However, because many journals have only a single chief-editor, measuring the international diversity of chief-editors at the level of the journal requires a modified approach:,In the analysis below we also compute diversity of chief editors by pooling all chief editors in the referenced category.

Diversity measures were computed for 14228 journal editorial boards. Boards were stratified by type (review, editor, chief), license (open, closed), and open science policy (TOPS-ranked). The primary analysis compared mean diversity (with bootstrapped confidence intervals) across groups, supplemented by anova analyses for each board type. (See the appendix, for anova results and comprehensive category percentages.) 
Figure five shows differences in gender and international diversity by board type, OA status, and open science policy: A number of differences are both substantially large and statistically significant: gender diversity was substantially lower for editorial boards ( $>7 \%$ ) of open access journals, for the review boards of non-open science, open access journals (> 6\%), and for the review boards of open-science journals vs. closed science journals (> 4\%). However, international diversity was substantially higher (> 11\%) for open access journal review boards. (All differences are significant at $p<.05$ level, we report exact $p$-values in a supplementary table).

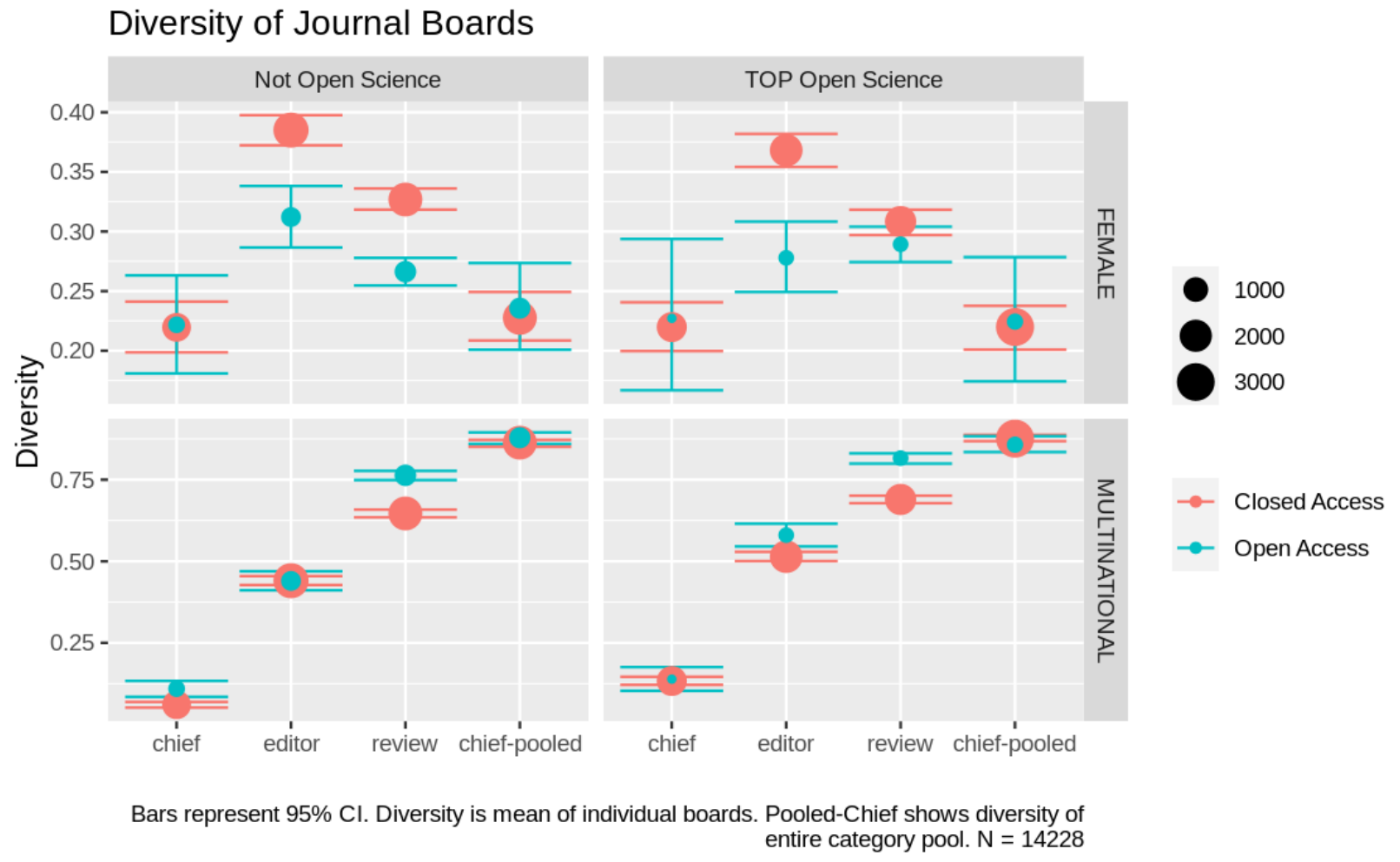

Figure 5: Diversity by journal OA and TOP status.

At the board level, the editor and review boards of OA journals are generally less balanced by gender, but more diverse internationally. The exception to this pattern is that there is no 
difference in the international diversity of open- vs closed- access journal editorial boards outside of TOPS open-science journals.

This unexpected pattern warrants further investigation. And we note that this difference is not due to the differential prevalence of OA journals in different fields: The pattern of OA journals being more internationally diverse and less diverse by gender continues to hold at the field level, for approximately two-thirds of subfields -- it is not an example of Simpson's paradox. Moreover, if the OA aggregate results were reweighted to match the disciplinary proportions of closed-access journals, the differences between OA and non-OA categories becomes even larger. 
Finally, in Figure 6, we examine the pattern of gender and national diversity by journal discipline and role. Within each discipline editor-in-chief pool is the most male-dominated role, and the editorial board the most balanced. For international diversity the relative integration of reviewers and editors is reversed so that diversity is greatest among the chief editor pool, and least among the editorial board.This unexpected pattern which occurs in almost every discipline-- we conjecture it is in part driven by the relative sizes of boards.

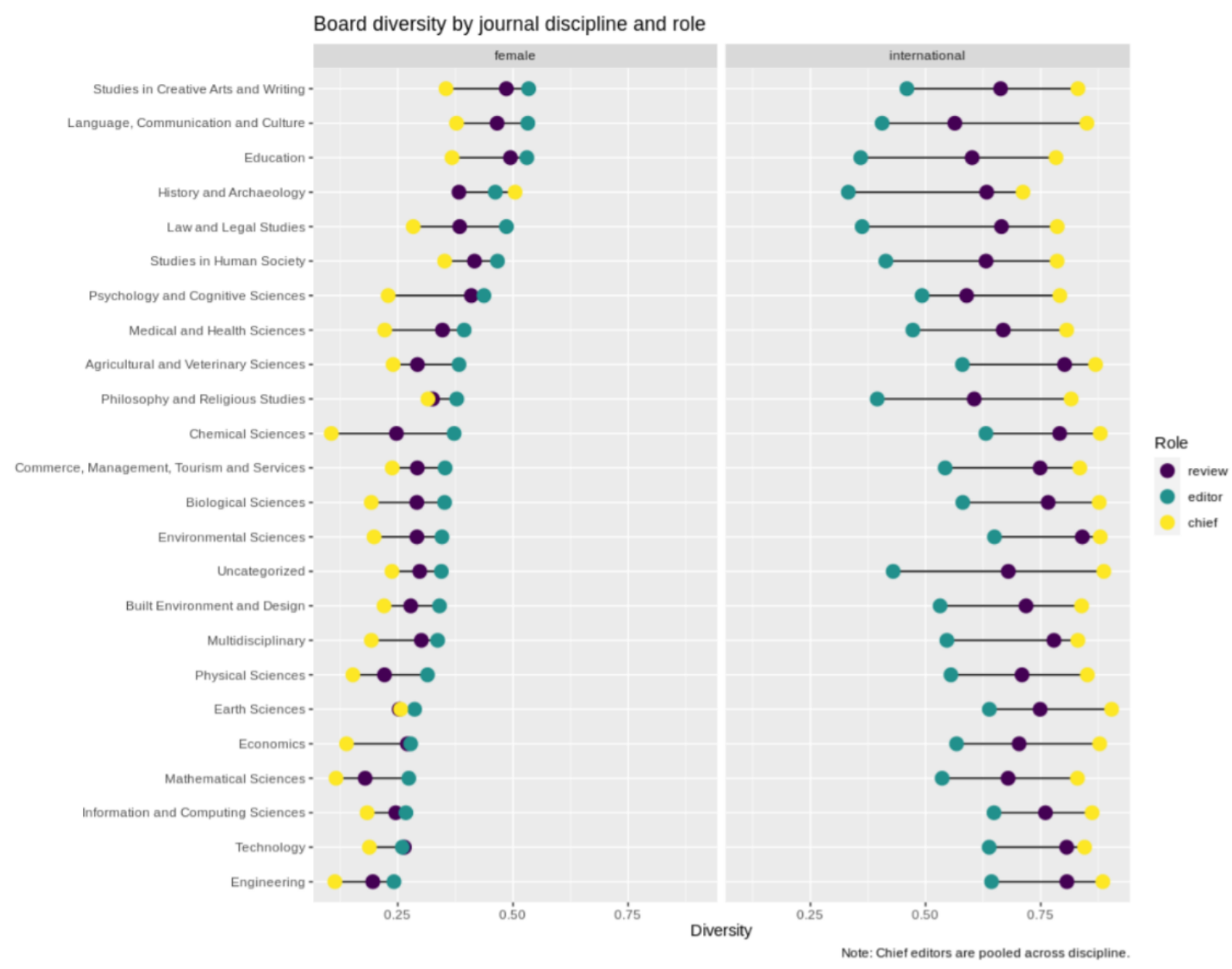

Figure 6. Editor diversity by journal discipline and role

The role of editor-in-chief is most male-dominated in chemical sciences, economics, and engineering. This pattern is more pronounced than in preWomen are best represented in history and archaeology, education, languages and communication, studies in human society, and 
creative arts and writing. National diversity is most prevalent in environmental sciences, engineering, technology, agricultural and veterinary, and chemical sciences, and all are relatively male-dominated. On the other hand, some of those disciplines with the least national diversity, including languages and communication, education, human society, and history/archaeology, have a relatively high representation of women. In short, these data do not reveal a general pattern of inclusiveness versus segregation across disciplines.

\subsection{Journal board network structure}

Of course, many characteristics other than gender and national institutions may form the basis for inclusion bias. Although the data does not support measuring other characteristics of editors directly, we apply exploratory network analysis to identify clusters of individual editors that are potentially overrepresented on journal boards. By matching on name and affiliation, we identify individuals who serve on multiple boards, then use these individuals to construct a co-occurrence network of journals by assigning edges between every journal that shares at least one board member.

Note that using names to identify editors may elide connections in which a single editor serves on multiple journals but changes name or affiliation across journals during the period of their editorship. We recommend that journals move to using ORCIDs in reporting editorial board membership -- which would eliminate this underreporting [41]. Notwithstanding, this undercount is unlikely to affect the overall finding of a power-law distribution, the field-level rankings, or the characterization of the tails of the distribution -- which are the features of interest in this analysis. 
The number of editorships held by individuals follows a power-law distribution. Only 417 editors (less than one percent) serve on more than one journal. Table 4 shows the distribution of multiple editorships.

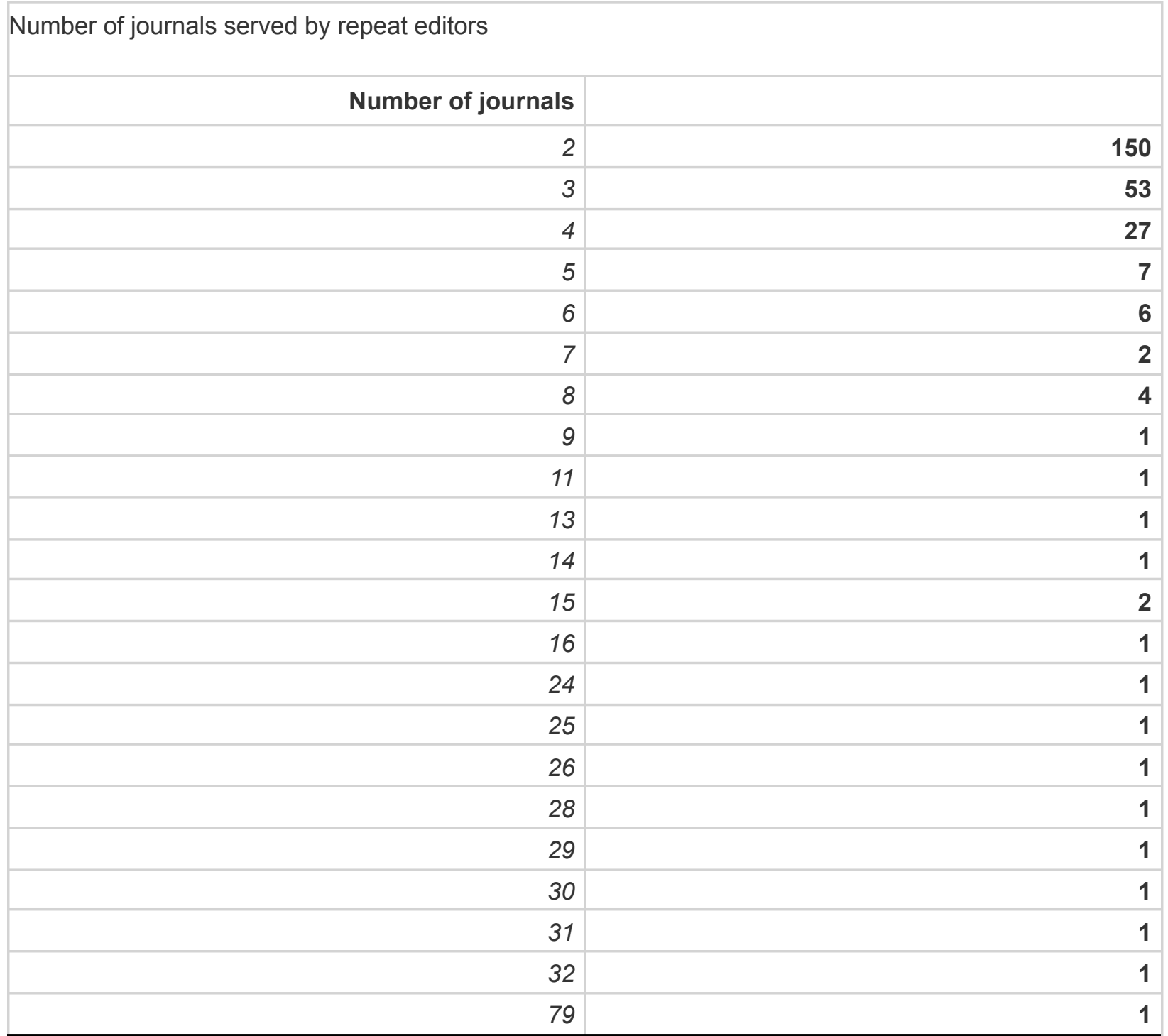

Table 4. Number of editors serving on multiple journals. 
Surprisingly, less than half of journals share any editorial connections to another journal. This contrasts with the high level of interconnectivity reported by Burgess and Shaw in their studies of elite business and management journals [2]. Figure 7 visualizes the connections among journals with at least one connection to another journal. We use a stress-majorization algorithm [42] to lay out the graph so that the clusters are easily identifiable.

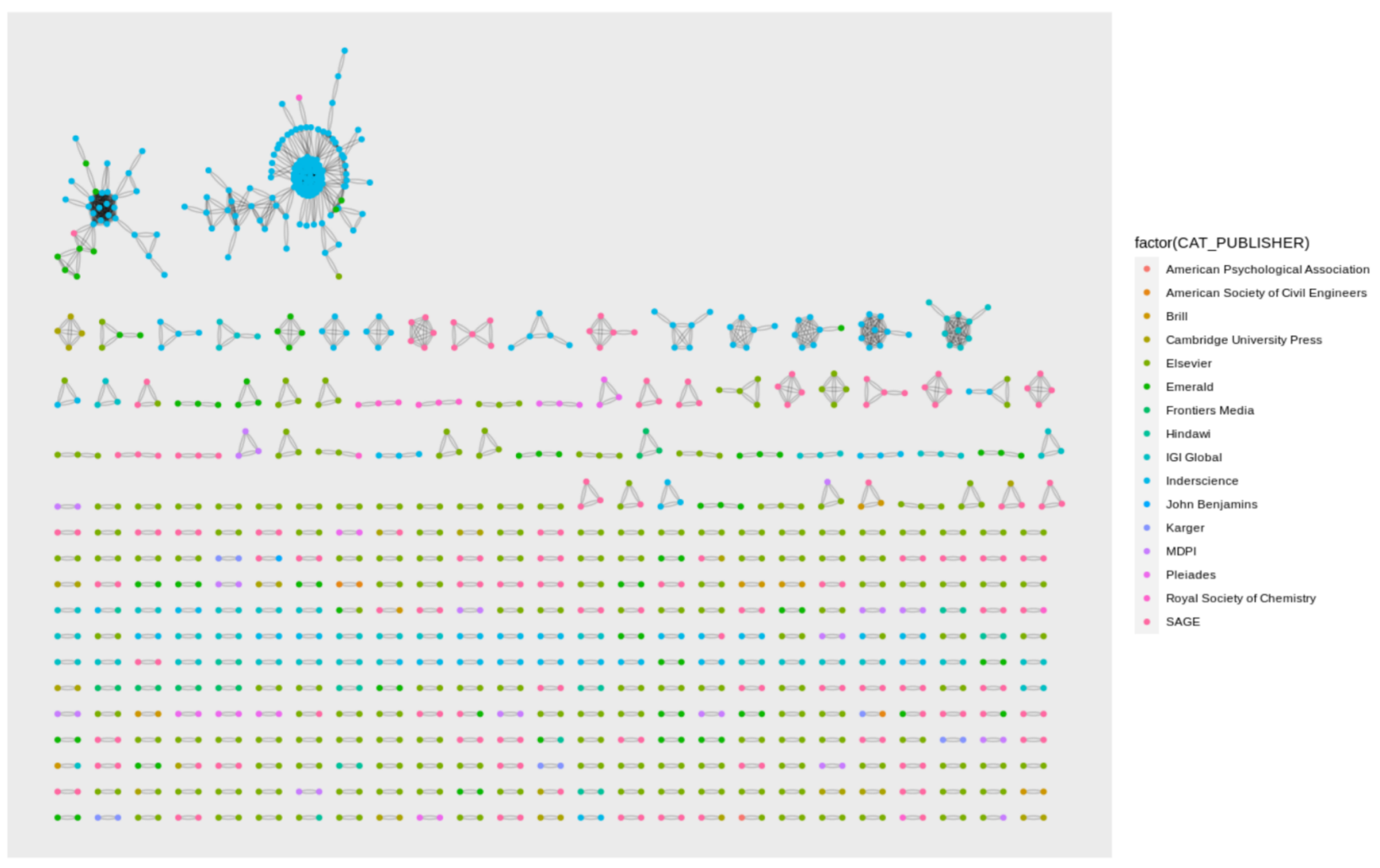

Fig 7. Editorial connections among journals. 
The distribution of journal clique sizes, shown in Table 5, follows a rough power-law distribution: While 379 journals (6\%) form one large interconnected cluster through shared editorships, 90\% of journals are part of clusters of less than four journals, and over $76 \%$ of journals do not share editors with any other journals.

\section{Distribution of Editorial Board Clusters}

\begin{tabular}{|l|l|l|l|l|l|l|l|l|l|}
\hline 2 & 3 & 4 & 5 & 6 & 7 & 9 & 10 & 33 & 145 \\
\hline 313 & 44 & 14 & 4 & 2 & 1 & 1 & 1 & 1 & 1 \\
\hline
\end{tabular}

Table 5. Distribution of journal clique sizes.

Generally, a power-law distribution is not surprising in a network of this type. However, the large clusters are outliers not only in size but in other characteristics. In particular, this analysis raises two concerns:

First, a tiny fraction of editors $(<1 \%$ ) serve on over three journals -- with a handful serving simultaneously on dozens of boards. This statistical pattern suggests gaming behavior (such as "honorary" editorship) by editors or publishers.

Second, the vast majority of editors serving on $>3$ boards serve at journals published by Inderscience. In particular, approximately two dozen editors served collectively on the boards of over 140 distinct Inderscience journals -- creating the largest interconnected journal cluster. Surprisingly, the same editors serve on boards of journals in quite different specializations or disciplines. This unusual statistical pattern suggests, at best, a lack of coordination by publishers when vetting editors or, at worst, a strategy to inflate editorial boards. 


\section{DISCUSSION}

We show that, on the whole, editorial boards remain dominated by men -- and heavily weighted towards editors from the US and Great Britain. Gender and international diversity varies by field, and the boards of journals in some fields are internationally diverse -- however, editorial boards have a substantially greater proportion of men in every field.

Further, this analysis shows that the top of the editorial hierarchy -- editors in chief -- is the most male-dominated and nationally homogeneous. The boards at lower levels have greater representation of women and more national diversity. However, while national diversity is greater among review boards than editor boards, the reverse is true concerning gender. Women are better represented at the middle level of editors than they are on editorial review boards.

Thus, among these seventeen publishers, more than six thousand journals, and almost half a million individuals, the gender and national origin hierarchies observed across academia are clearly reflected. Moreover, despite substantial variation, these hierarchies hold across all subject disciplines.

We do not find a strong association between open access, research transparency, and editorial team diversity. In fact, there is a somewhat greater representation of women in the lower ranks of closed-access journals than among those that use open-access publishing models. On the other hand, although the relationships are weak, there is somewhat greater national diversity among OA journals (at the lowest level), and in TOP journals. Further, we cite numerous cases of relatively male-dominated disciplines that exhibit relatively high levels of national diversity, and some with less national diversity that have a higher representation of women.

We also find that there is a small cluster of editors that are substantially overrepresented in Inderscience journals. However, this appears to result from gaps in the vetting process -- and not due to gender or nationality biases. 
A realistic assessment of the relationship among open access and research transparency, on the one hand, and gender and national diversity, on the other, suggests that the two are not strongly related. Openness and inclusion should be pursued in their own right. Evaluating progress will require not only that scholars regularly analyze the aspects of the operation of scholarly communication that are currently visible, but also that publishers make available richer information on inclusion and participation.

\section{APPENDIX: SUPPLEMENTARY FIGURES AND TABLES}

\section{Board International Diversity by OA and TOPS status}

\begin{tabular}{|c|c|c|c|c|c|c|}
\hline & \multicolumn{3}{|c|}{ CLOSED ACCESS } & \multicolumn{3}{|c|}{ OPEN ACCESS } \\
\hline & MEAN & $(95 \% \mathrm{CI})$ & (N) & MEAN & $(95 \% \mathrm{CI})$ & (N) \\
\hline \multicolumn{7}{|c|}{ NOT OPEN SCIENCE } \\
\hline review & 0.64657219 & $63 \%-66 \%$ & 2281 & 0.7633510 & $75 \%-78 \%$ & 689 \\
\hline editor & 0.44039808 & $43 \%-45 \%$ & 2493 & 0.4397535 & $41 \%-47 \%$ & 550 \\
\hline chief & 0.06025289 & $5 \%-7 \%$ & 1483 & 0.1096888 & $8 \%-13 \%$ & 360 \\
\hline chief-pooled & 0.86340000 & $85 \%-87 \%$ & 2282 & 0.8786000 & $86 \%-89 \%$ & 656 \\
\hline \multicolumn{7}{|c|}{ TOP OPEN SCIENCE } \\
\hline review & 0.68936925 & $68 \%-70 \%$ & 1851 & 0.8159850 & $80 \%-83 \%$ & 308 \\
\hline editor & 0.51406394 & $50 \%-53 \%$ & 2071 & 0.5801442 & $55 \%-62 \%$ & 306 \\
\hline chief & 0.13323540 & $12 \%-15 \%$ & 1667 & 0.1388211 & $10 \%-18 \%$ & 169 \\
\hline chief-pooled & 0.87580000 & $87 \%-89 \%$ & 3044 & 0.8572000 & $84 \%-88 \%$ & 335 \\
\hline
\end{tabular}

Note: Diversity measures are computed per-board for editorial and review boards, and pooled for chief-editor roles. 
Board Gender Diversity by OA and TOPS status

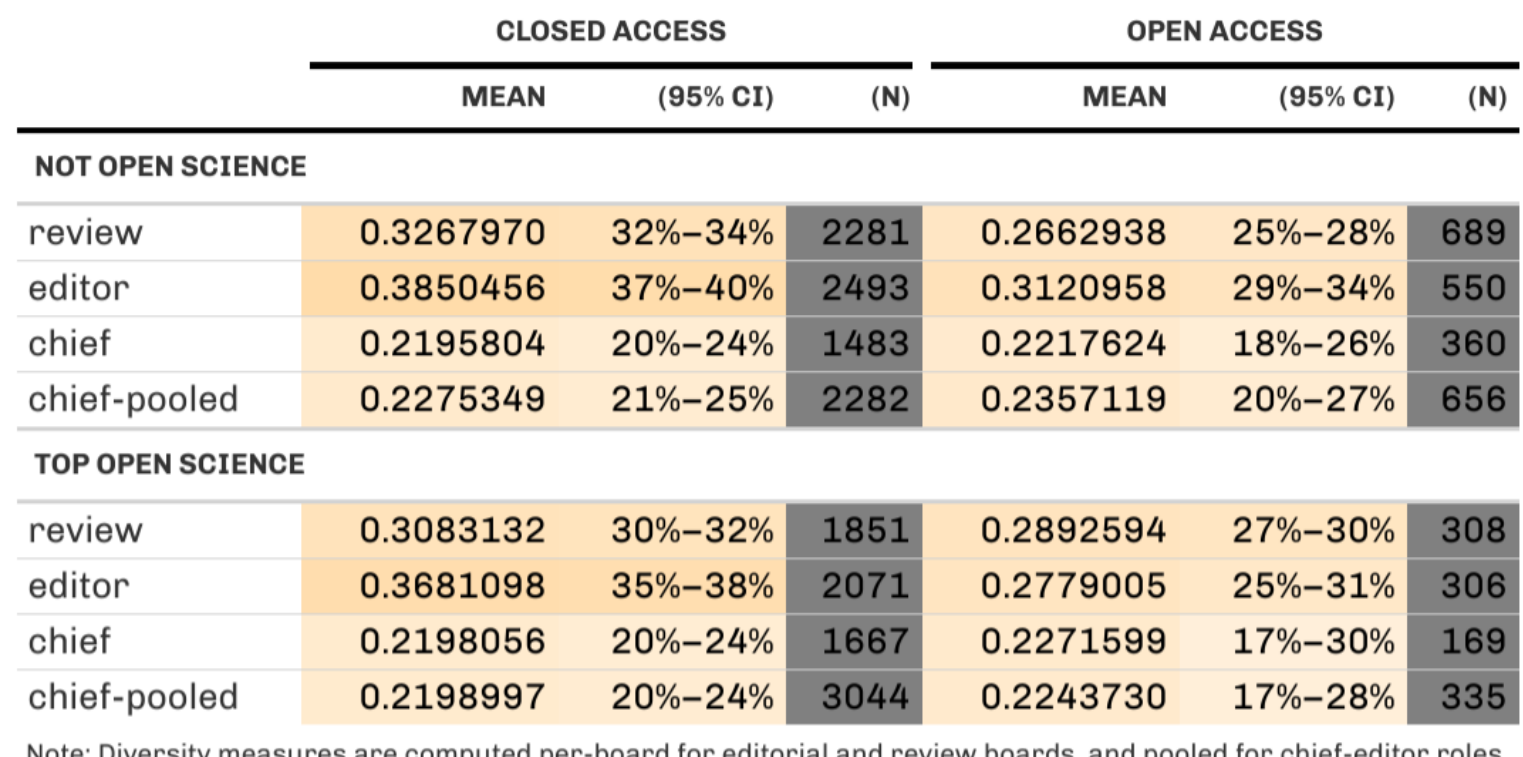

Table A1a,b: Diversity by journal OA and TOP status, with individual N, and bootstrapped confidence intervals. 
TOP Open Science and Open Access as a predictor of diversity ESTIMATE

P-VALUE

\begin{tabular}{|c|c|c|}
\hline \multicolumn{3}{|l|}{ REVIEW - FEMALE } \\
\hline TOP Open Science & 1.52 & $p=0.218$ \\
\hline Open Access & 42.86 & $p=6.52 e-11$ \\
\hline \multicolumn{3}{|l|}{ REVIEW - INTERNATIONAL } \\
\hline TOP Open Science & 1.52 & $p=0.218$ \\
\hline Open Access & 42.86 & $p=6.52 e-11$ \\
\hline \multicolumn{3}{|l|}{ EDITOR - FEMALE } \\
\hline TOP Open Science & 3.84 & $p=0.0501$ \\
\hline Open Access & 48.45 & $p=3.85 e-12$ \\
\hline \multicolumn{3}{|l|}{ EDITOR - INTERNATIONAL } \\
\hline TOP Open Science & 3.84 & $p=0.0501$ \\
\hline Open Access & 48.45 & $p=3.85 e-12$ \\
\hline \multicolumn{3}{|l|}{ CHIEF - FEMALE } \\
\hline TOP Open Science & 0.00 & $\mathrm{p}=0.973$ \\
\hline Open Access & 0.04 & $p=0.837$ \\
\hline \multicolumn{3}{|l|}{ CHIEF - INTERNATIONAL } \\
\hline TOP Open Science & 0.00 & $\mathrm{p}=0.973$ \\
\hline Open Access & 0.04 & $p=0.837$ \\
\hline
\end{tabular}

Note: Separate ANOVA's are run for each editorial board and index of diversity.

Table A2: Diversity by journal OA and TOP status, ANOVA Results

\section{ACKNOWLEDGMENTS}

Author Statement and Acknowledgements. Authors are listed in alphabetical order. We describe contributions to the paper using a standard taxonomy [43]. All authors take equal responsibility for the article in its current form. All authors collaborated in creating the first draft of the manuscript; all authors were primarily responsible for redrafting the manuscript in its current 
form; all authors contributed to review and revision. All authors contributed to the article's

conception (including core ideas, analytical framework, and statement of research questions).

All authors contributed to the project administration and to the writing process through direct

writing, critical review, and commentary.

\section{REFERENCES}

1. Huffman ML, Cohen PN, Pearlman J. Engendering Change: Organizational Dynamics and Workplace Gender Desegregation, 1975-2005. Administrative Science Quarterly. 2010;55: 255-277. doi:10.2189/asqu.2010.55.2.255

2. Burgess TF, Shaw NE. Editorial Board Membership of Management and Business Journals: A Social Network Analysis Study of the Financial Times 40. British Journal of Management. 2010;21: 627-648. doi:https://doi.org/10.1111/j.1467-8551.2010.00701.x

3. Stainback K, Tomaskovic-Devey D, Skaggs S. Organizational Approaches to Inequality: Inertia, Relative Power, and Environments. Annual Review of Sociology. 2010;36: 225-247. doi:10.1146/annurev-soc-070308-120014

4. Stainback K, Kleiner S, Skaggs S. Women in Power: Undoing or Redoing the Gendered Organization? Gender \& Society. 2016;30: 109-135. doi:10.1177/0891243215602906

5. Marvel JD. Change Agents or Cogs in the Machine? Female Managers and Unofficial Gender Equality in Federal Agencies. Public Performance \& Management Review. 2018;41: 328-364. doi:10.1080/15309576.2017.1400990

6. Hillman AJ, Shropshire C, Cannella AA. Organizational Predictors of Women on Corporate Boards. AMJ. 2007;50: 941-952. doi:10.5465/amj.2007.26279222

7. Thomas EG, Jayabalasingham B, Collins T, Geertzen J, Bui C, Dominici F. Gender Disparities in Invited Commentary Authorship in 2459 Medical Journals. JAMA Network Open. 2019;2: e1913682-e1913682. doi:10.1001/jamanetworkopen.2019.13682

8. Murray D, Siler K, Larivière V, Chan WM, Collings AM, Raymond J, et al. Author-Reviewer Homophily in Peer Review. bioRxiv. 2019; 400515. doi:10.1101/400515

9. Helmer M, Schottdorf M, Neef A, Battaglia D. Gender bias in scholarly peer review. Rodgers P, editor. eLife. 2017;6: e21718. doi:10.7554/eLife.21718

10. Holman L, Stuart-Fox D, Hauser CE. The gender gap in science: How long until women are equally represented? PLOS Biology. 2018;16: e2004956. doi:10.1371/journal.pbio.2004956

11. Topaz CM, Sen S. Gender Representation on Journal Editorial Boards in the Mathematical Sciences. PLOS ONE. 2016;11: e0161357. doi:10.1371/journal.pone.0161357

12. Metz I, Harzing A-W, Zyphur MJ. Of Journal Editors and Editorial Boards: Who Are the Trailblazers in Increasing Editorial Board Gender Equality? British Journal of Management. 2016;27: 712-726. doi:https://doi.org/10.1111/1467-8551.12133

13. Metz I, Harzing A-W. Gender Diversity in Editorial Boards of Management Journals. AMLE. 2009;8: 540-557. doi:10.5465/amle.8.4.zqr540

14. Cho AH, Johnson SA, Schuman CE, Adler JM, Gonzalez O, Graves SJ, et al. Women are underrepresented on the editorial boards of journals in environmental biology and natural resource management. PeerJ. 2014;2: e542. doi:10.7717/peerj.542

15. Jalilianhasanpour $R$, Charkhchi $P$, Mirbolouk M, Yousem DM. Underrepresentation of Women on Radiology Editorial Boards. Journal of the American College of Radiology. 2019;16: 115-120. doi:10.1016/j.jacr.2018.08.017

16. Pflibsen LR, Foley BM, Bernard RW, Lee GK, Neville MR, Almader-Douglas D, et al. 
Representation of Women on Plastic Surgery Journal Editorial Boards in the United States. Aesthetic Surgery Journal. 2021 [cited 9 Apr 2021]. doi:10.1093/asj/sjab034

17. Clark J, Horton R. What is The Lancet doing about gender and diversity? The Lancet. 2019;393: 508-510. doi:10.1016/S0140-6736(19)30289-2

18. Okagbue HI, Atayero AA, Adamu MO, Oguntunde PE, Opanuga AA, Bishop SA. Dataset and analysis of editorial board composition of 165 Hindawi journals indexed and abstracted in PubMed based on affiliations. Data in Brief. 2018;19: 520-525. doi:10.1016/j.dib.2018.05.065

19. Wu D, Lu X, Li J, Li J. Does the institutional diversity of editorial boards increase journal quality? The case economics field. Scientometrics. 2020;124: 1579-1597. doi:10.1007/s11192-020-03505-6

20. Espin J, Palmas S, Carrasco-Rueda F, Riemer K, Allen PE, Berkebile N, et al. A persistent lack of international representation on editorial boards in environmental biology. PLOS Biology. 2017;15: e2002760. doi:10.1371/journal.pbio.2002760

21. Palser ER, Lazerwitz M, Fotopoulou A. Gender and geographical disparity in editorial boards of journals in psychology and neuroscience. Nat Neurosci. 2022;25: 272-279. doi:10.1038/s41593-022-01012-w

22. Bhaumik S, Jagnoor J. Diversity in the editorial boards of global health journals. BMJ Global Health. 2019;4: e001909. doi:10.1136/bmjgh-2019-001909

23. Goyanes M, Demeter M. How the Geographic Diversity of Editorial Boards Affects What Is Published in JCR-Ranked Communication Journals. Journalism \& Mass Communication Quarterly. 2020;97: 1123-1148. doi:10.1177/1077699020904169

24. Murphy MC, Mejia AF, Mejia J, Yan X, Cheryan S, Dasgupta N, et al. Open science, communal culture, and women's participation in the movement to improve science. PNAS. 2020;117: 24154-24164. doi:10.1073/pnas.1921320117

25. Altman M, Bourg C. A Grand Challenges-Based Research Agenda for Scholarly Communication and Information Science. 2018 [cited 29 Jan 2019]. doi:10.21428/62b3421f

26. King MM, Frederickson M. The Pandemic Penalty: The gendered effects of COVID-19 on scientific productivity. SocArXiv; 2020. doi:10.31235/osf.io/8hp7m

27. Pacher A, Heck T, Schoch K. Open Editors: A Dataset of Scholarly Journals' Editorial Board Positions. SocArXiv; 2021 Mar. doi:10.31235/osf.io/jvzq7

28. Haddow G, Hammarfelt B. Quality, impact, and quantification: Indicators and metrics use by social scientists. Journal of the Association for Information Science and Technology. 2019;70: 16-26. doi:10.1002/asi.24097

29. Morrison H. Directory of Open Access Journals (DOAJ). 2008 [cited 23 Apr 2021]. doi:10.14288/1.0107434

30. Nosek BA, Alter G, Banks GC, Borsboom D, Bowman SD, Breckler SJ, et al. Promoting an open research culture. Science. 2015;348: 1422-1425. doi:10.1126/science.aab2374

31. Wickham, Hadley, Grolemund, Garrett. R for data science: import, tidy, transform, visualize, and model data. O'Reilly Media, Inc.; 2016.

32. Keyes O. humaniformat: A Parser for Human Names. 2016. Available: https://CRAN.R-project.org/package=humaniformat

33. Blevins C, Mullen L. Jane, John... Leslie? A Historical Method for Algorithmic Gender Prediction. DHQ: Digital Humanities Quarterly. 2015;9.

34. Mullen L. gender: Predict Gender from Names Using Historical Data. 2020. Available: https://github.com/ropensci/gender

35. Larivière V, Ni C, Gingras Y, Cronin B, Sugimoto CR. Bibliometrics: Global gender disparities in science. Nature. 2013;504: 211-213. doi:10.1038/504211a

36. Karimi F, Wagner C, Lemmerich F, Jadidi M, Strohmaier M. Inferring gender from names on the web: A comparative evaluation of gender detection methods. Proceedings of the 25th International conference companion on World Wide Web. 2016. pp. 53-54. 
37. Ruggles S, McCaa R, Sobek M, Cleveland L. The IPUMS collaboration: integrating and disseminating the world's population microdata. Journal of demographic economics. 2015;81: 203-216.

38. Acheson E, De Sabbata S, Purves RS. A quantitative analysis of global gazetteers: Patterns of coverage for common feature types. Computers, Environment and Urban Systems. 2017;64: 309-320. doi:10.1016/j.compenvurbsys.2017.03.007

39. Harrington P. Generating Geographic Terms for Streaming Videos Using Python: A Comparative Analysis. Code4Lib Journal. 2019.

40. Rhoades SA. The Herfindahl-Hirschman index. Federal Reserve Bulletin. 1993; 188-189.

41. Waggoner PD. The hhi Package: Streamlined Calculation and Visualization of Herfindahl-Hirschman Index Scores. Journal of Open Source Software. 2018;3: 828. doi:10.21105/joss.00828

42. Gansner ER, Koren Y, North S. Graph drawing by stress majorization. International Symposium on Graph Drawing. Springer; 2004. pp. 239-250.

43. Allen L, Scott J, Brand A, Hlava M, Altman M. Publishing: Credit where credit is due. Nature. 2014;508: 312-313. doi:10.1038/508312a 